AC 2012-4238: UNDERGRADUATE RESEARCH: DOES IT PROMOTE GRADUATE EDUCATION? CREATING FUTURE GRADUATE STUDENTS IN ENGINEERING

Dr. Timothy M. Hodges P.E., Virginia Military Institute

Timothy M. Hodges is a professor of mechanical engineering and Charles S. Luck, Jr., '20, Institute Professor.

Dr. Elizabeth White Baker, Wake Forest University 


\title{
Undergraduate Research: Does it promote graduate education? Creating future graduate students in engineering.
}

\author{
Abstract \\ The Undergrad Only Colleges Mechanical Engineering Department would like to promote \\ students to choose to pursue graduate education. This paper outlines a new program that \\ introduces cadets to the world of graduate education. The core of the program is to partner with \\ existing graduate schools to germinate the seed of future work in graduate engineering education. \\ The goal is to foster the benefits of graduate education and the career enhancement that obtaining \\ the education affords. We also believe that participation in the program makes the \\ undergraduate student a better communicator and logical thinker with the ultimate goal of \\ introducing the students to graduate studies in engineering. In this paper we introduce the \\ conceptual framework of the program and the results of its early implementation. We will also \\ address the future planning for continued longitudinal study of the program.
}

\section{Overview}

Alexander (1) suggests that the essential features of a successful summer program include: a meaningful research experience, the opportunity to interact with role models and other undergraduate students forming a "community". In the Bauer(2) study researchers surveyed three groups: those who participated in research experience as part of a "university organized" program, those who participated in research on their own with a faculty member or those who did not do research as part of their undergraduate experience. In the first two groups those surveyed were more likely to go on to graduate school, reported a greater satisfaction in their undergraduate experience, and reported increases in intellectual curiosity, research skills and communication skills. A study by Foertsch (3) found that students participating in undergraduate research felt the experience was a necessary and important step in getting into graduate school and the relationship with a mentor was critical to their success. Russell (5) found that undergraduate student researchers said that the research experience clarified their career interests, increased their understanding and their confidence.

Why should engineering educators promote graduate work? A graduate degree will increase the technical background in the focus area. Most master's degrees require 30 hours of course work and that translates into 10 different courses in the focus area. Obtaining a graduate degree will make you a cut above your peers and allow you to perform more interesting work. In addition a graduate degree requires you to perform research and publish a thesis. This independent work distinguishes those with a graduate degree as one who can think independently and can express those thoughts in a coherent manner. The technical gains that are made in the pursuit of the graduate education make clear the limits of engineering analysis and design. This instills a better understanding of the ethical responsibilities associated with creating solutions for the public. For these reasons the Undergrad Only College is promoting graduate education.

Currently the Undergrad Only College fosters the opportunity for undergraduate research with a faculty mentor. This one-on-one environment for academically motivated students, along with financial and material support, has been in place for several years. Students propose a research project in coordination with a faculty mentor, with the student as the principal investigator. The 
proposal is vetted by a faculty committee to determine whether the research will be funded. In many instances the completed work is published by the students. However, in this environment, there is no opportunity for the engineering students to be exposed to a graduate engineering research environment.

A new joint cooperative program was created this past summer with the intent of exposing students to graduate work in engineering. The Undergrad Only College and a Grad Institution partnered to create and jointly fund summer research projects for the Undergrad Only Colleges students. The students propose a research project that is jointly mentored by a Grad Institution faculty member and a faculty member at the home Undergrad Only College. After the projects were selected, the student spends the summer at the Grad Institution conducting a study or experimental work to complete the research project. The program broadens the research opportunities for the undergraduate student by enabling the student to go to the Grad Institution and interact with graduate faculty and students.

The initiative is to promote and instill a desire for undergraduate students to pursue graduate education. The idea is to place the undergrad student in a graduate environment so that the research work being done may spur them to choose to pursue further education. An additional benefit to both institutions is an understanding between the institutions. The understanding is that there will be a guaranteed admission to a certain number of qualified undergraduate students in any graduate program offered by the Grad Institution.

There was a group of students that completed undergraduate research projects at the Undergrad Only College. There was a second group of students that completed research at the Graduate Institution. The two groups are compared below.

\section{Data Collected}

In this study a survey was conducted based on SURE-II by Lopatto (4). The data was collected to compare the change in student attitudes toward a graduate education between those that stayed at the Undergrad Only College and those who went to the Graduate Institution. The students were surveyed that completed the older summer research program at the home Undergrad Only College. The students participated with a faculty mentor and completed a research project and each was asked to complete a survey of their experiences. The students that participated at the Grad Institution were also given the same survey and asked to complete the survey at the end of their experience at the Grad Institution. The numbers of students participating was small so this preliminary work is an initial assessment of the program and its impact.

\section{Benefits of Undergraduate Research}

In this section the student was asked in a survey to consider the possible benefits that were gained from the research experience. The students were asked to select a number that reflects their most recent research experience. For example, if you were experienced at working independently and did not increase this skill by doing your most recent research, then give that item a low number. If your most recent research experience gave you additional ability and confidence for working independently, then give that item a high number. The reported values are averages of the responses collected one month after they completed the program. 
The scale for the measuring the gain was as follows:

1: No gain or very small gain

2: Small gain

3: Moderate gain

4: Large gain

5: Very large gain

The measured items were:

1) Clarification of a career path

2) Skill in the interpretation of results

3) Tolerance for obstacles faced in the research process

4) Readiness for more demanding research

5) Understanding how knowledge is constructed

6) Understanding of the research process in your field

7) Ability to integrate theory and practice

8) Understanding how scientists work on real problems

9) Understanding that scientific assertions require supporting evidence

10) Ability to analyze data and other information

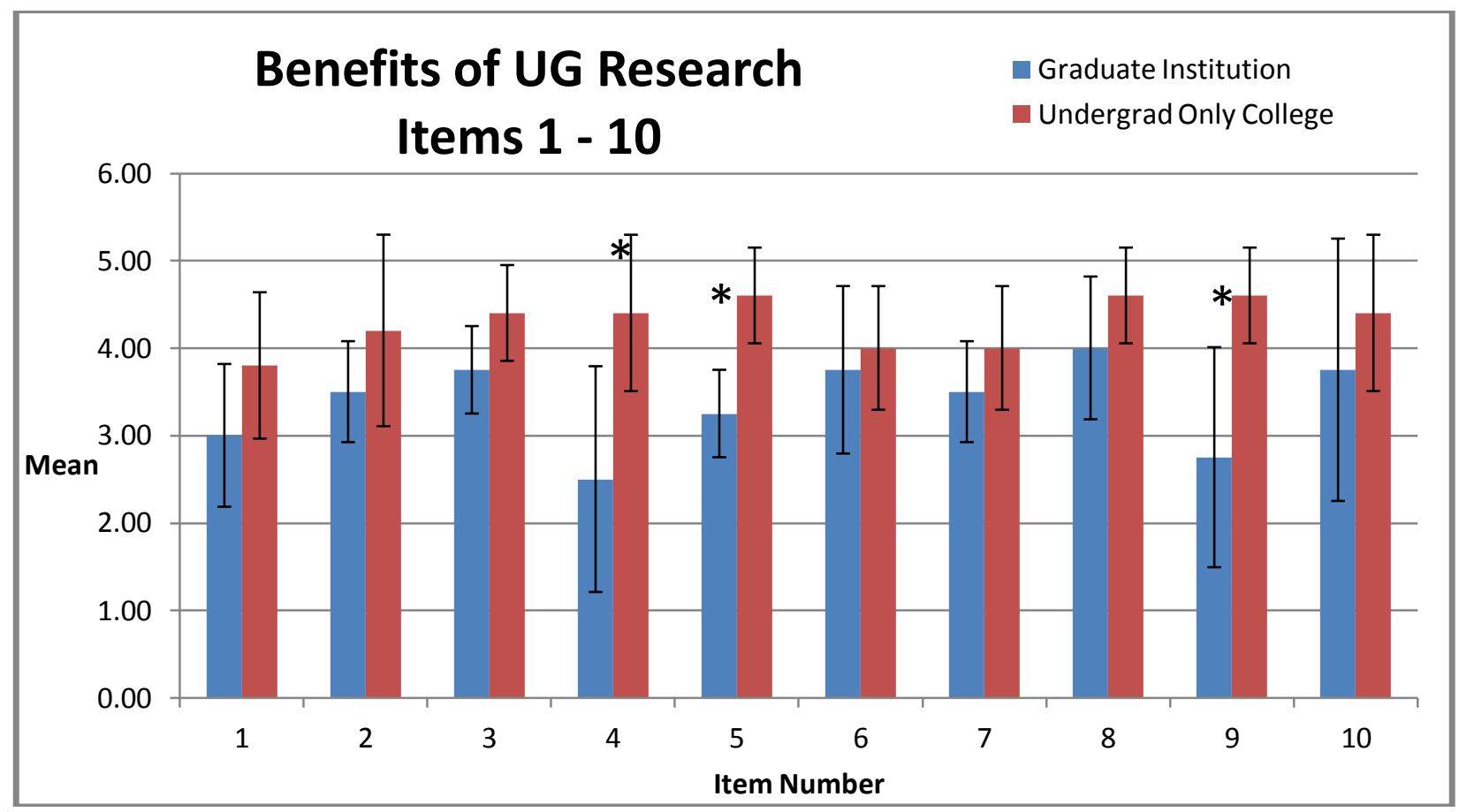

* Items 4, 5, and 9 are statistically significant values as determined by the student T-test. 
11) Understanding science

12) Learning ethical conduct in your field

13) Learning laboratory techniques

14) Ability to read and understand primary literature

15) Skill in how to give an effective oral presentation

16) Skill in science writing

17) Self-confidence

18) Understanding of how scientists think

19) Learning to work independently

20) Being part of a learning community

21) Confidence in my potential to be a teacher of science

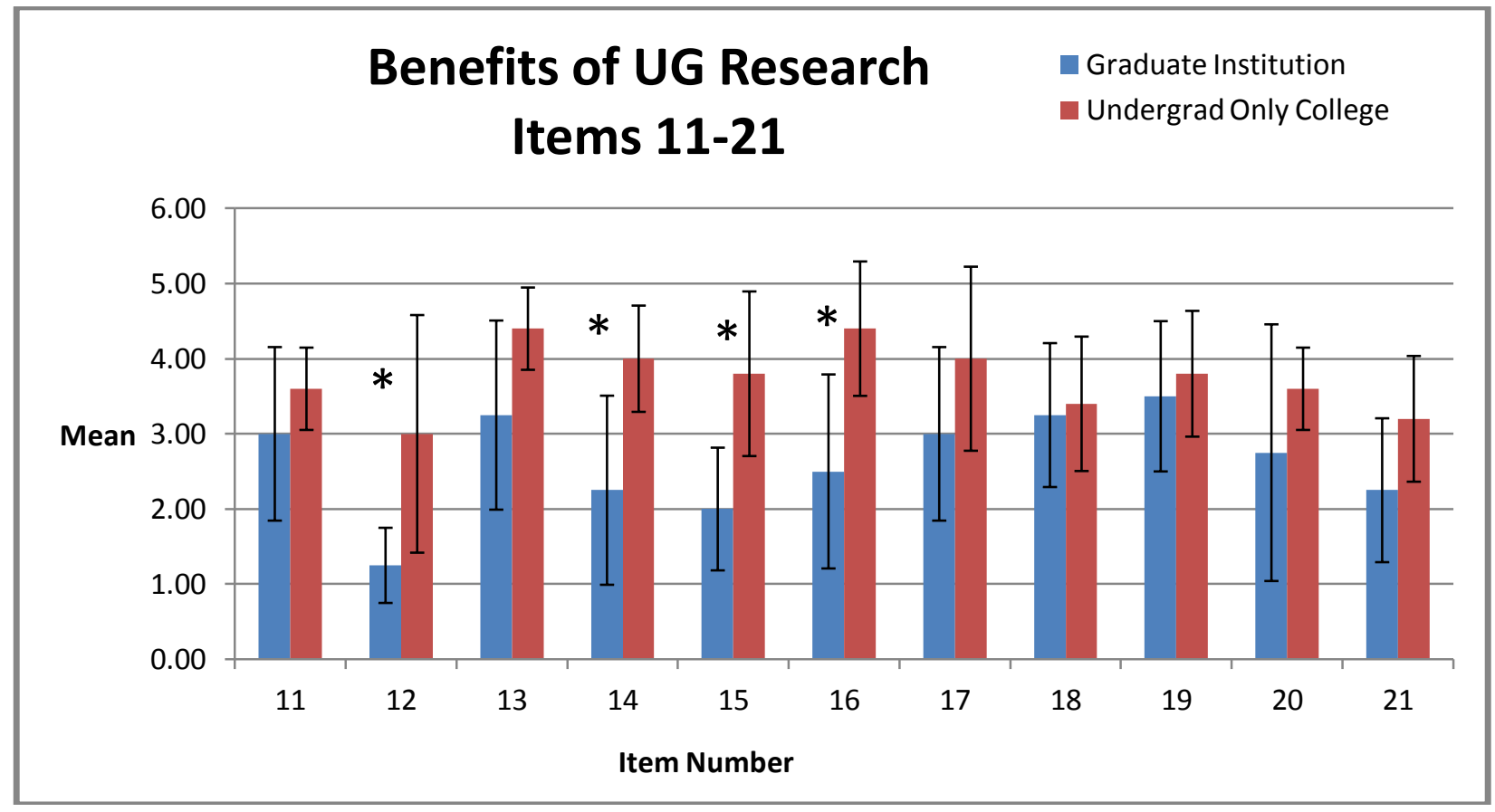

* Items $12,14,15$, and 16 are statistically significant values as determined by the student T-test. 


\section{Analysis of the Benefits Data}

The cohort were from a closely knit community where they all know each other and their academic prowess was equivalent in terms of their grade point average. In items 4, 5, 9, 12, 14,15 , and 16 the T-test shows there is a significant statistical difference. In item 4, "Readiness for more Demanding Research" and item 5, "Understanding how knowledge is constructed." the students at the Undergrad Only College indicate that they were not as ready to pursue higher level work. Item 9, "Understanding that scientific assertions require supporting evidence.", the Undergrad Only College students indicate that basic research knowledge is not as easy to develop as learning in a lecture course or laboratory experience. Item 14, " Ability to read and understand primary literature.', item 15, "Skill in how to give an effective oral presentation.", and item 16, "Skill in science writing.", indicates that the students at the Undergrad Only College found that their education was just beginning in what a good technical reader, writer, or speaker needs to be. In item 12, The results here show that those students at the Undergrad Only College had more of an emphasis on "Ethical conduct" or it just wasn't discussed at the Grad Institution. The Undergrad Only College has a very strong Honor System and the students at the home institution were more likely to associate this with their experience.

\section{Findings}

Those that participated in the program were two thirds rising seniors and one third rising juniors, all mechanical engineering majors (8) save one physics major. The majority had not completed any research project in the past with only one student having past research experience. The student's plans before beginning the research program had $60 \%$ of the Undergrad Only College with a desire to pursue graduate education and $25 \%$ of the Grad Institution students. The student plans after the research program was completed had $60 \%$ of the Undergrad Only College with a desire to pursue graduate education and $0 \%$ of the Graduate Institution Students. The change is attributed to those who went to the Grad Institution and discovered that they did not like graduate education. Before the program there were $0 \%$ of the Undergrad Only College not interested in pursuing post-graduate education and after the summer program there were $25 \%$ who are not interested. Before the program there were $25 \%$ of the Graduate Institution students not interested in pursuing post-graduate education and after the summer program there were $50 \%$ who were not interest in pursuing graduate work.

\section{Overall Experience}

The students at both the Undergrad Only College and the Graduate Institution were asked a series of questions about their overall experience.

1) Think about the number of people you worked with.

a. $60 \%$ of Undergrad Only said they preferred the same number and $50 \%$ of the Graduate said they preferred the same number

b. $40 \%$ of the Undergrad Only preferred to work with more people and $25 \%$ of the Graduate said they preferred more people

c. $25 \%$ of the Graduate said they wanted to work with fewer people.

2) What was the frequency in which you work with other people? 
a. $80 \%$ of the Undergrad Only said they preferred the same frequency and $75 \%$ of the Graduate said they preferred the same frequency.

b. $20 \%$ of the Undergrad only said they preferred more frequency and $25 \%$ of the Graduate said they preferred more frequency.

3) What did they think of the expectation about the research experience?

a. Experience was worse than expected - 0\% Undergrad Only, 25\% Grad

b. Experience met expectations - 20\% Undergrad Only, 25\% Grad

c. Experience was better than expected - 20\% Undergrad Only, 25\% Grad

d. Experience was much better than expected $-60 \%$ Undergrad Only, 25\% Grad

4) What did they think about their mentor/ professor?

a. 50\% of those in the Grad experience thought the mentor was average.

b. $100 \%$ of the Undergrad Only thought the mentor was above average or outstanding and the 50\% of the Grad students thought the mentor was above average or outstanding.

5) Think about the other undergraduate students you worked with.

a. Working with other students did not affect the research experience. $-20 \%$ Undergrad Only and 25\% Grad

b. Working with other students moderately enhanced the research experience. $-40 \%$ Undergrad Only and $0 \%$ Grad

c. Prefer not to Answer - 40\% Undergrad Only and $75 \%$ Grad

6) Would you choose to do another research experience as an Undergraduate?

a. $80 \%$ of the Undergrad Only and $50 \%$ of the Grad would be likely or very likely

b. Prefer not to Answer 20\% Undergrad Only and 50\% Grad.

In each category the Undergrad Only students seemed to have a much better experience than the Graduate Institution students. Another observation is that at the Undergrad Only College professors are very assessable and were a positive influence. The experience with other students was a negative in that many choose not to even answer the question with a rating. This indicates that they preferred to be independent and not function as a team. The majority felt that the experience was positive and that they would want to do further research work.

\section{Initial Conclusion and Future Work}

This initial study indicates that some students who performed an undergraduate research experience are not encouraged to continue with post-graduate education. Students who participated in the summer were required to work continuously for about two years giving little time for reflection, relaxation and regeneration. Those that originally wanted to pursue postgraduate education where encouraged and those that had questioned the benefit were discouraged. This may truly make for a better graduate student once they get into a graduate program. The students that attended the Graduate Institution did not have that same benefit. In every category in the benefits section the gain was higher for those that were at the Undergrad Only College as reported in the survey. This is counter intuitive. It would seem that those that attended the Graduate Institution would have had more gain. Further work is necessary to determine whether the students attending the Graduate Institution were already at a higher level, therefore a larger gain were not possible. Those attending the Graduate Institution have gained a 
clearer view of the requirements for graduate education. Therefore they will be better prepared when they do decide to pursue an advanced degree. The future plans are to: a) perform a longitudinal study collecting data over several years, and b) investigate the reason for the difference in the gains.

\section{Bibliography}

1) Alexander, B., Foertsch, J., Daffinrud, S. and Tapia, R. 2000. The spend a summer with a scientist (SaS) program at Rice University: a study of program outcomes and essential elements 19911997. Council on Undergraduate Research Quarterly 20(3): 127-133

2) Bauer, K.W. and J.S. Bennett. 2003. Alumni perceptions used to assess undergraduate research experience. Journal of Higher Education 74: 210-230.

3) Foertsch, J., Alexander, B. and Penberthy, D. 2000. Summer research opportunity programs (SROPs) for minority undergraduates: a longitudinal study of program outcomes 1986-1996. Council of Undergraduate Research Quarterly 20 (3): 114-119

4) Lopatto, D, 2007 Undergraduate research experiences support science career decisions and active learning. CBE-Life Sciences Education, 6, 297-306.

5) Russell, S.H., Hancock, M.P. and McCullough J. 2007. Benefits of Undergraduate Research Experiences. Science 316: 548-549. 